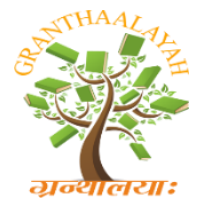

\author{
INTERNATIONAL JOURNAL OF RESEARCH \\ GRANTHAALAYAH \\ A knowledge Repository
}

Social

\title{
THE ISSUE ON DETERMINATION OF TYPOLOGICAL FEATURES OF PEOPLE, COMMITTING CRIMINAL OFFENSES RELATED TO THE FORGERY OF EXCISABLE GOODS, AS AN ELEMENT OF THE CRIMINALISTIC CHARACTERISTICS
}

\author{
Ayupova Zauresh ${ }^{1}$, Begaliyev Yernar ${ }^{2}$, Uspanov Zholdybay ${ }^{3}$ \\ ${ }^{1}$ Master of Law. Institutions «Academy of Law Enforcement Authorities under the General \\ Prosecutor's Office» of the Republic of Kazakhstan, Doctoral Student, e-mail: \\ zauresh.ayupova@bk.ru; 021804, 16 Republic str., Koschy village, Tselinograddstrict, Akmola \\ region, Republic of Kazakhstan \\ ${ }^{2}$ Doctor of Juridical Science, Associate Professor. Institutions «Academy of Law Enforcement \\ Authorities under the General Prosecutor's Office» of the Republic of Kazakhstan, Professor of \\ Special Legal Disciplines, e-mail: ernar-begaliev@ mail.ru, 021804, 16 Republic str., Koschy \\ Village, Tselinograd District, Akmola Region, Republic of Kazakhstan \\ ${ }^{3}$ Candidate of Juridical Sciences, Professor, Academician of the International Informatization \\ Academy. Institutions «Kazakh Academy of Labour and Social Relations» Republic of \\ Kazakhstan, Dean of the Faculty of Social Sciences and Law, e-mail: zhakemvd@ mail.ru, \\ 050004, 9 NauryzbayBatyr Str., Almaty, Republic of Kazakhstan
}

\begin{abstract}
In the article «The issue on determination of typological features of people, committing criminal offenses related to the forgery of excisable goods, as an element of the criminalistic characteristics» prepared by doctoral student Ayupova Z.N.; Professor of the Department of Special Legal Disciplines, Doctor of juridical Science Begaliev E.N; Dean of the Faculty of Social Sciences and Law, candidate of juridical Sciences, Professor UspanovZh.T. The main purpose of this article is to identify the most characteristic features of an intruder's personality and to formulate recommendations aimed at improving the process of investigating criminal offenses related to falsification of excise goods. The article deals with the issue of theoretical interpretation of the concept of "criminalistic characterization of crimes" and "typology of personality" as its element. The analysis of the reference paper is given regarding the study of the typology of persons committing criminal offenses; as well as the problems that arise in determining the subject of the crime and the ways to solve them. The types of persons committing criminal offenses connected with forgery of excisable products as exogenous and endogenous types of intruders are investigated; classified by the object of encroachment, the nature of criminal acts, the degree of public danger. The concepts of socially-adoptive, socially-disadaptive type of personality of persons who commit this category of a criminal offense are disclosed. The structure of the personality of the intruder who deals in the falsification of excisable goods has been compiled and examined through socio-demographic, criminally-legal, socially significant physiological features and moral properties. The analysis of methods for establishing a suspect person is given, the main types of malefactors and their functions are identified in the production of a surrogate excise
\end{abstract}


product. Recommendations for persons conducting investigations into criminal cases related to forgery of excise goods are developed.

Keywords: Excise Goods; Forgery of Excise Goods; Economic Crimes; Typology of Personality; Criminalistic Characteristics; Features of Criminal Types; The Establishment of The Suspect; Criminology; Operational-Investigative Activities; Operational-Investigative Measures; The Subject of The Crime; Psychology; Methods of Crime Investigation; Methods of Establishing; The Suspect.

Cite This Article: Ayupova Zauresh, Begaliyev Yernar, and Uspanov Zholdybay. (2019). "THE ISSUE ON DETERMINATION OF TYPOLOGICAL FEATURES OF PEOPLE, COMMITTING CRIMINAL OFFENSES RELATED TO THE FORGERY OF EXCISABLE GOODS, AS AN ELEMENT OF THE CRIMINALISTIC CHARACTERISTICS.” International Journal of Research - Granthaalayah, 7(1), 315-327. 10.29121/granthaalayah.v7.i1.2019.1057.

\section{Introduction}

The typology of people committing criminal offenses is one of the most significant and basic elements of the criminalistic characteristics. As far as each person's social program set by the outside world, refracted through the intellect and the sensually-emotional sphere, gradually becomes an internal content of the individual, the possession of knowledge and understanding of such a category of modern criminal science as an intruder's personality being an element of the criminalistic characteristics of crimes related to with forgery of excisable goods, has the paramount importance for increasing the effectiveness of law enforcement in the disclosure and investigation of criminal offenses of the specified type.

Nowadays, the media publish a significant number of different videos, programs, feature films, serials and shows, the stories of which describe the mechanisms of committing crimes in the sphere of falsification of excisable goods. Even without having some experience and knowledge in the field of counterfeiting and its methods, to date, everyone has the opportunity to possess theoretical knowledge about the methods of fermenting and distilling alcohol, alcoholic beverages and medications with its content; methods of production and composition of raw materials for oil and all possible substitutes for increasing octane numbers in the composition in the stage-by-stage processing; instructions for the qualitative application of various inscriptions on spare parts of cars, their methods of installation, welding and replacement; methods of applying paints, types of printing and their use in drawing, copying, etc. In addition, through the perception of information broadcast and published in the media, without difficulty, one can learn about the methods of law enforcement officers, which they use in the detection of criminal offenses etc. Undoubtedly, all of the above, contributes to raising the professional level of the perpetrators of criminal offenses and undoubtedly serves as an instruction, as well as guidance on the organization, commission and concealment of such criminal offenses, and the destruction of traces. It is for this reason that persons investigating crimes related to forgery of excisable goods deal with crimes committed in conditions of non-obviousness, and the identity of the suspect, at the initial stage of the investigation, is not established or the information about his/her personality is not enough. Despite the identification of criminal offenses of this group of crimes, followed by its registration, "the investigation stage does not always end with the presentation of the charge. The statistical 
dynamics of criminal cases sent to court also has no stability. Over the past nine years, the maximum number of criminal cases, completed by the production and sent to the court was - $66.7 \%$ in 2011. The least number of criminal cases sent to court was in 2012, during the peak of the crime increase in this area" [1, p.42].

For this reason, considering that the basis for the criminalistic characterization of crimes is the study and generalization of investigative and judicial practice, the law enforcement officers need to establish the criminalistic characteristics in order to submit the objective and well-founded versions of a criminal offense in the sphere of counterfeit excise goods and other.

Due to study of various types of criminal offenses, at the stages of its preparation, commission and concealment, the elements of the criminalistic characteristics of certain types (groups) of crimes are revealed. It facilitates the person conducting the investigation in the formation of typical investigative versions; in drawing up a plan for the further investigation of the crime, that is, unlike the criminal law, it is of an auxiliary nature.

Thus, we come to the conclusion that the criminalistic characterization of crimes is a scientific abstraction which is a collection of criminally-relevant information about crimes of a certain type with the purpose of promptly disclosure, properly investigation and effectively warning.

\section{Materials and Methods}

were dialectical method of scientific knowledge, as well as formal-logical, historical-legal, comparative-legal, statistical, system-structural and other private-scientific methods of research of social and legal phenomena.

\section{Results and Discussion}

Our literature reference material research on the concept and content of criminalistic characteristics of crimes in the sphere of falsification of excisable goods indicates that the criminalistic characterization of any crimes must be considered through its practical significance as a basis:

- in the development of methods for investigating certain types of criminal offenses;

- to organize a full, objective and comprehensive investigation of a criminal offense;

- in the recommendation and subsequent verification of investigative versions in order to establish all the circumstances of a criminal event.

Analyzing the above, to some extent, one can find reflection in the definition of the corresponding criminalistic characteristics of the concept. Despite the significant differences in the definition of its concept, many authors such as T.V. Averyanova, R.S. Belkin, V.P. Bakhin, I.A. Vozgrin, Yu.G. Korukhov incline to believe that its meaning is to synthesize the most characteristic criminal information about criminal offenses of a certain type necessary for effective and intensive disclosure and investigation [2, p.668; 3, p.18; 4, p.273].

According to V.N. Isayenko, the criminalistic characterization of crimes should be considered in the following values: "1) as a collection of data on the most common characteristics of persons 
who previously committed crimes of one kind or another; 2) as an aggregate of data on their actions in the period of preparation for the commission of a crime, during and after its commission (criminal conduct), the use of which can provide a positive result in establishing and exposing the perpetrators" [5, p.41]. Falling into line with this point of view, we come to the conclusion that the establishment of separate elements of the event, during the crime investigating process in the sphere of excisable goods counterfeiting, contributes to the restoration of the overall picture of the committed crime.

In addition to the task of criminalistic characterization of crimes as the direct influence on efficiency and optimization of the investigation procedure, R.L. Akhmedsh in points to other task that, in his opinion, are the most practically significant:

1) Disclosure of the content of criminalistic concepts, the emergence of which is an objective content of the process of scientific knowledge.

2) Optimization of the crime investigation process due to reasonable submission of the most probable (typical) investigative and operational-search versions, using the criminalistic characterization of the crime as the most likely model and orienting information.

3) Formation of the scientific basis of private methods.

4) Search for logical links between the elements of the criminalistic characteristics of crimes to identify the unknown element due to the known ones [6, p.16-18].

There are two categories of characteristics in the criminalistic science applied to the category of crimes investigated by us:

- Typical criminalistic characteristics of crimes;

- Individual criminalistic characteristics of crimes.

In our opinion, there is a direct and inverse connection between the two categories. Thus, as typical criminalistic characteristics of certain types of crimes as falsification of excisable goods and their varieties are the basis for development of a private investigation methodology. But, it is undeniable that their abstraction and formation can be carried out only by studying the criminalistic characteristics of specific types of crimes. In this regard, we share the opinion of G.A. Gustov, who believes that "the characterization of a specific crime is a picture (information model), reflecting a single assault, and is compiled by the investigator on the basis of the materials of a specific case, serves as an information base for theoretical criminalistic research" [7, p.83].

As to the development of methods for investigating certain types of criminal offenses, such as the falsification of excisable goods, the characterization of the individual who committed this crime and is the bearer of criminalistic information is of distinctive interest. In addition, the identity of the crime figure has a significant impact on other elements of the criminalistic characteristics and determines their content. Considering that the way, mechanism and conditions of the criminal offense, in many cases, directly depends on the properties of a person committed the crime, the most effective and relevant in the study of the subject of crimes in the sphere of falsification of excisable goods, we consider the approach of V.K. Gavlo, who wrote that: "The personality must be studied as a word-forming object, a source of information about the crime committed and as a means of its disclosure" [8, p. 197]. 
We believe that the establishment of a person typology who commits a criminal offense related to falsification of excisable products is required to:

- assist law enforcement officers in the study of persons who are investigating the category of criminal offenses;

- study and establish the reasons that contribute to the commission of such head offenses;

- develop the methods for exposing the criminal activity committed;

- determine and select the most effective tactical and psychological techniques for subsequent application to a person, and educational measures.

The lack of identity information about the persons who commit falsification of excisable goods "negates the completeness, comprehensiveness and objectivity of the preliminary investigation, as well as the inquiry about the individualization of the punishment imposed by the court to the guilty party, about success of the convict's correction, and about the identification and suppression of the reasons and conditions contributing to the commission of a crime" [9, p. 58], and completely agree with the opinion of A.M. Yakovlev, that "studying the identity of a person committed the crime, we can find such qualities and properties that are not separated but in combination with the negative impact of the external factors, and as a result of a conscious decision they lead a person to commit a crime" [10, p.69].

Analysis of opinions of scientific psychologists who studied the typological characteristics of various criminal persons who committed crimes of various categories, showed that their types can be differentiated into endogenous and exogenous ones.

The endogenous individuals are the persons whose "causes of wrongful conduct are explained primarily by their psychological constitution, i.e. special characteristics of the person, forming a predisposition to this crime, their constant physical and mental qualities, mental abilities, views and beliefs, world outlook, inclinations in character to this mode of action with which the crime is internally connected"[11, p. 59].

The exogenous type commits crimes for the sake of freeing him/herself from serious suffering that threatens him/her or is experiencing him/her [11, p. 61].

When studying the special books concerning the identity of persons committing criminal offenses connected with the forgery of excisable products, we have found that it is characterized with a set of typological features that are the root of the typology of persons who committed criminal offenses. When establishing and compiling such typological characteristics of the crime figure's personality, there is an acute need for using different approaches and criteria: what inner motives prompted a person to commit a crime etc.

Having established the above circumstances, it is possible to consider the analysis of a subject of a crime. The following groups are determined:

- mercenary;

- violent;

- mercenary-violent. 
Representatives of the mercenary subjects group in crimes related to falsification of excise products, are the most common. Thus, studying the practice of the investigated category of criminal offenses showed that the main motives for committing such illegal actions are the financial (material) enrichment.

Representatives of the second and third groups rarely commit falsification of excise goods; violence is used in rare cases when a crime figure, in the absence of certain skills and knowledge, requires the deliberate coercion of another person endowed with such abilities to commit acts associated with the commission of illegal actions.

By nature, degree of public danger, the criminal types of crime figures dealing in forgery of excisable goods, are subdivided as follows:

- random type uniting individuals who first committed a crime as a result of an accidental coincidence of circumstances with a general socially positive personal orientation;

- situational type of personality of crime figures who committed a crime under the influence of unfavorable conditions of their personality formation, but, in general, characterized more positively than negatively;

- - unstable type uniting individuals who also committed a crime for the first time, but who previously committed various kinds of offenses, immoral acts;

- -malicious type, including persons who committed two or more willful crimes;

- particularly dangerous type of personality of crime figures recognized as dangerous or especially dangerous recidivists for committed serious crimes, etc. [12, p.81-82].

On the basis of the types of persons who have committed criminal offenses, we believe that it is necessary to develop typologies of persons falsifying excisable products on the subjective side and, depending on the form of guilt, to divide them into willful or committed by coercion, deception and abuse of trust, etc.

In the course of research of the psychological characteristics of individuals who committed various criminal acts, our attention was drawn to the aggregate quality of the individual as social adaptability, which directly affects the actions, behaviors and behavior of people in a variety of situations (criminal situations are no exception). Studying the totality of the qualities of individuals committing criminal offenses in the sphere of forgery of excisable products, we have established that the level of their social adaptability is determined by the level of intellectual and spiritual development, the neuropsychic state, emotional-volitional stability, the motivational sphere, including value orientations, world outlook, avoidance of failure.

We divided the persons above into two groups, tentatively:

1) Socially adaptive (possesses a high level of emotional and volitional stability, long-acting psychophysical loads, tolerance to stresses, the stenotic type of response in difficult, critical situations. In practice, this type is most often or longer unrevealed and is spread among professional crime figures, leaders of the organized criminal groups and gangster groups). According to scientific research in the field of socio-adaptive type of the persons committing criminal offenses, the following factors are identified that contribute to determining its level:

- their neuro-psychic, emotional-volitional stability; 
- intellectual level of the subject development;

- motivational sphere of the personality, including not only the motives for achieving, avoiding failure, but also more complex formations, such as value orientations, the worldview of the personality.

2) Socially-disadaptive (possesses neurotic symptomatology, expressed accentuated character properties on the basis of hyperimmune-unstable, epileptoid and some other types, mental anomalies, psychotic disorders, psychopathic personality traits; such people have low emotional-volitional stability, reduced resistance to the stress. They have quite primitive needs, like spending time in constant entertainment drinking alcohol, using drugs; and due to the fact that such needs cannot always be satisfied, they have an uncontrolled state and increased aggressiveness) [13, pp.26-28].

Socially-disadaptive persons are much more often than others under the strong influence of affectively colored states, frustrations, emotions of anger, etc.

We agree with the classification of criminal types, developed by A.G. Kovalyov, who subdivides the subjects studied, into the following three types:

- globalcriminaltype;

- partialcriminaltype;

- precriminaltype [14, p.49-51].

Different sciences of law study identity of the crime figures in specific, for each science, purposes and determine the various legal states of a person: thus, criminal law operates with the concept of "subject of crime"; criminal trial - "suspect"; criminal-executive law - "convict", etc. and has a clearly defined legal status, rights and responsibilities. In contrast, the criminological concept of "the identity of the offender" is not mentioned in the law. Criminology considers a person as a cumulative species of a person whose social and legal specifics are related to the fact of committing a criminal offense.

The concept of a person committing a criminal offense is "the totality of its socially significant properties that, in combination with external conditions (situation), affect criminal behavior" [15, p.74-75]; this direction remains the central problem of the whole science of criminology.

Nevertheless, the selection of persons committing crimes from the whole mass of people is made, first of all, on the basis of a legal criterion, namely, the fact that a person commits a crime. We can agree with some exceptions that "definition of the identity of the criminal figure as a person committed the crime has a formal connotation" [16, p.84].

However, we cannot rely solely on a legal criterion, since the introduction of social criteria gives grounds for considering any crime as "disagreement of the individual's behavior with the society. This understanding of the personality serves as a basis for substantiating the need and possibility of the preventive impact on the individual associated with the tasks of neutralizing, weakening, and, if possible, elimination of negative qualities due to the positive ones as well as the development of the latter" [17, p.52].

Undoubtedly, persons who have committed criminal offenses in the sphere of counterfeit excise goods are characterized by a significant number of inherent characteristics. Therefore, an 
important task, both in the scientific and in the practical sense, arises: to identify the typical features of such personalities, except for the ability to violate the criminal law at least once.

For this purpose, the criminology developed a category named as the personality structure of the crime figure. According to the structure developed by A.I. Dolgolva, it is necessary to distinguish the following groups of characteristics: 1) socio-demographic; 2) criminally-legal; 3) social occurrence in various spheres of life (or social ties); 4) moral; 5) psychological; 6) physical (biological) [18, p. 399]. From the point of view of V.D. Malkov, the personality structure of the crime figure is necessary to be included with such substructures (features) as: biophysiological, socio-demographic and socio-role, moral-psychological, criminally-legal and criminological [19, p.84]. We will consider the most widespread and systematized structure of the personality features of a crime figure according to Yu.V. Byshevsky: "1. Socio-demographic features. 2. Criminallylegal features. 3. Moral properties and psychological features" [20, p.214] and socially significant physiological features, which together, in our opinion, have a direct relation to persons dealing in falsification of excise goods:

1) Socio-demographic features such as: gender, age, social, marital and official status, profession, level of prosperity, availability or absence of a permanent place of residence, etc. Some scientists, as an independent element of the personality structure of a crime figure, stand out "its occurrence in various spheres of social life" [21, p. 92]. As far as we are talking about the position of an individual in the system of the public and social relations, his/her belonging to certain social groups and the roles performed, this group of features can be classified as socio-demographic, but in the context of dynamics and not in statistics.

2) Criminally-legal features are inherent only to the persons making falsification of excisable production. These are the data on the type of crime committed, its motivation, forms of guilt, individual or group nature of criminal activity, criminal history, etc. These features reflect the characteristics, properties of crime, its individual species (groups), as well as specific roles.

3) Moral properties and psychological features. This element of the personality structure of a crime figure covers their subjective world. In addition, this group of features is often subdivided into subspecies, in particular, the need-motivational sphere (needs, inclinations, interests, motives), value-normative characteristics of consciousness (views, beliefs, value orientations) is singled out. Psychological features are analyzed in relation to the intellectual, emotional and volitional spheres, etc.

4) Socially significant physiological features. These include: state of health, diseases (including hereditary), features of the physical constitution. The features of this group have factors that are of wider meaning for the characterization of the crime figure personality that impede the process of the personality socialization, such as congenital corporal defects, severe chronic diseases that limit the individual's possibilities for education, professional training and employment, leisure, other normotypicoccurence of vital activity. Negative, including potentially criminogenic, effects of biological (biophysical, biopsychological) factors on behavior of an individual should be neutralized by measures aimed at the socialization of the person, upbringing combined with psychotherapeutic and other correction, creating a friendly accessible habitat for persons with disabilities [22, p.84]. 
A very productive personality theory of crime figures, as an integral entity for scientific purposes that, in our view, has a direct bearing on persons dealing in falsification of excise products, is developed by Yu.M. Antonyan, V.N. Kudryavtsev, V.Ye. Eminov in their book. They propose to consider them on the following substructures:

- biological (temperament, age and sexual characteristics, type of nervous system, etc.);

- individual (memory, perception, will, feelings, thinking, emotions, etc.);

- $\quad$ social (knowledge, skills, experience, habits, etc.);

- motivational (hobby, inclination, attraction, personality direction, etc.) [23, p.18-19].

We consider it necessary to establish the above-mentioned personality sub-structures of crime figures who commit falsification of excise products, as they are related to its psychological characteristics, and each of them can have criminal aspects. Also, it is necessary to consider the fact that such a person is characterized with a number of specific features inherent only to persons committing criminal offenses of this type of crime.

Based on the questionnaire results conducted for the category of people most frequently carrying out falsification of excise products, the following was obtained: sales representatives - 10\%; single-subject specialists in the production sphere - 32\%; multi-skilled persons - 18\%; employees of entertainment establishments - $6 \%$; unemployed - $13 \%$, others $-21 \%$.

It is necessary to note the fact that persons, who commit forgery of excisable goods, have a high level of knowledge, creative abilities and possess skills of creative activity etc.

Considering that more and more requirements are being applied to the packaging of any product, including excisable goods, it is obvious that this is the main reason for its continuous improvement. More and more products have their own trademark; each excisable product is marked; various protective elements appeared that effectively complicate the process of forgery. Due to this reason, the persons directly involved in the production of falsified excise stamps and trademarks require deep theoretical skills in a wide variety of knowledge area, as the technology for production of such stamps and signs is of great secret. As a rule, they have special knowledge and practice in the field of publishing and printing industry; have skills of using various equipment for photocopying, printing; are skilled in various methods of applying paints.

As to the producers of alcohol and alcoholic products, in most cases, these are the people with knowledge in classification and methods of alcohol preparing because production of counterfeit alcohol (in most cases, the main component in production of surrogate alcohol products) requires determination of the specific amount of distillation, selection of substitute raw materials, skills of packaging finished products, detection of chemical composition etc.

Considering the fact that falsification of tobacco products and products with heated tobacco, nicotine-containing liquids for use in electronic cigarettes is made due to the qualitative, quantitative, informational, cost and assortment falsification, a person who carries out its production must have all the above qualities and skills. In addition, in the production of alcohol and tobacco products, various types of equipment are used; it requires special knowledge as well. Obtaining of such knowledge is possible due to the special training, working places or using similar equipment. 
Along with the listed excisable goods, a significant turnover in their falsification is gained with: gasoline, diesel fuel, crude oil and gas condensate. In order to produce their surrogate, it is necessary to have work experience in oil refineries; ability to properly distil a natural resource; experience of distillation of gasoline fractions, liquefied gas, diesel fractions, as well as fuel oil; special chemical knowledge for determining octane numbers in raw materials, applying the correct formulas in calculating the composition of each raw material; experience in the use of technology and equipment the above actions are carried out on. For this reason, persons who are engaged in falsification of such excisable goods are the representatives of the technical mindset.

The products, subject to the number of excisable goods, having a wide popularity in production among falsifiers, are the motor vehicles intended for the transportation of 10 or more people with an engine capacity of more than 3,000 cubic centimeters, with the exception of minibuses, buses and trolleybuses; cars and other motor vehicles intended for the transport of people with an engine capacity of more than 3,000 cubic centimeters (except for cars with manual control or cars with manual control adapter specially designed for persons with disabilities); motor vehicles on the chassis of a passenger car with a platform for loads and a driver's cab separated from the cargo hold by a rigid stationary partition with an engine capacity of more than 3,000 cubic centimeters (except for manually operated cars or cars with manually operated adapters specially designed for persons with disabilities). Completely different categories of people are often involved in falsification of certain parts of a car and forgery of documents.

As to the first category of falsifiers, they are basically ordinary motorists. As a rule, the main part of our society, having a personal car, has certain skills in repairing, analyzing and selecting spare parts for the car. But we are talking about individuals who have studied in detail the mechanism for the compilation and operation of car spare parts; having wide knowledge of the types of materials used in the production of such parts and know their difference in quality; having education in the field of technical professions; being members of certain groups of motorists; or the employees of car service stations. All the above confirms the fact that they have necessary skills in the proper use of equipment for performing various repairs to the car and its parts.

Due to introduction of many innovations in the production of cars that constantly updated, even persons involved in the professional repair of cars are necessary to be classified in three types:

- persons involved in repairing second-hand units and assemblies for the fund of the restored spare parts for cars (most of them are specialists in the running and motor parts of a car);

- persons with knowledge in the field of electronics and digital equipment (these are the specialists review and repair of electronic parts of a car);

- persons with special knowledge in science of chemistry and physics, as well as in the art industry (professionals in painting and repair of body parts of cars).

- The most effective methods for identifying persons dealing in forgery of excisable goods include:

- Identity information obtained through the special investigation activities;

- Identity information obtained following the results of the investigative activities;

- Identity information obtained following the results of forensic examinations.

As a result of our questionnaire survey concerning the most effective use of methods for identifying persons involved in the investigation of the variety of criminal offenses, the following 
results were obtained: - identity information obtained through the special investigation activities 47\%; identity information obtained following the results of the investigative activities - 13\%; identity information obtained following the results of the forensic examination - 9\%, others - $31 \%$. In addition to the above qualities and skills of people dealing in falsification of excisable goods, the law enforcement officers need to establish the following circumstances:

- Whether a subject of the crime is capable, sane person who has reached the age of criminal responsibility;

- Characterizing data of the suspect (character reference from the place of study, work and residence; marital status, etc.);

- Information about study and work where the certain skills and knowledge have been obtained;

- Criminal record;

- Social position, social circle.

Another task is to determine the criminologically significant features of persons engaged in the production and sale of surrogate excise goods. Based on research of the books on specialized subjects concerning classification of the crime figure types, we can distinguish the following types of persons engaged in falsification of excisable goods:

- initiator;

- producer;

- distributor.

The coordination activity of the first type (initiator) is to distribute a criminal role, develop a plan for commission and concealment of a crime etc. "The initiator may not participate in a crime but act via other accomplices. The initiators, leaders of the organized groups or criminal communities are especially dangerous" [24, p.121].

A person engaged in production of surrogate products and falsification of excisable goods, is referred to the second type: producer.

Any person "able to make believe that the falsified products have all qualitative features that correspond to the original" [9, p.174] can act as the third type. In order to sell such a product, a distributor uses such influence methods as conviction, coercion and psychological impact.

\section{Conclusion}

Summarizing the analyzed issue on determination of the typological identity of persons committed forgery of excise goods as an element of criminological characteristics, we believe that for the purpose of fair and accurate justice to establish the causes and conditions contributing commission of a crime and appoint the correct and fair punishment, the court must operate with all the information about a subject of the crime set forth by us in the article.

Deep and comprehensive study of the crime figure identity, committed forgery of excise products, is of great importance for the punishment individualization, determination the optimal way of impact on the convicted person, organization and tactics of preventive work. 
In this regard, at the stage of pre-trial investigation, the law enforcement officials have to:

- develop an individual or typical characterization of persons committing crimes related to forgery of excisable products;

- determine the type of person who committed a criminal offense: endogenous or exogenous;

- determine a group for a person who committed the falsification of excise goods: mercenary, violent, mercenary-violent;

- identify the nature of public danger of a person who committed the criminal offense;

- determine the social adaptability of an individual;

- identify the typical features of a crime figure, except the ability to commit a criminal offense.

All the established circumstances about the crime figure personality committed a criminal offense related to the forgery of excisable products must be contained in the files of criminal investigation. Basing on these documents, the law enforcement officers will have an opportunity to identify the factors that affect the commission of this type of crime and use them in the process of investigation and consideration of the criminal case, as well as for planning and conducting individual preventive works.

\section{References}

[1] Ayupova Z.N. Current state and prospects for investigating criminal offenses in the sphere of forgery of excise products // Science and Life of Kazakhstan. - Astana, 2018. No.3 (58).

[2] Averyanova T.V, Belkin R.S, KorukhovYu.G., Rossinskaya E.R Criminalisticscience. - Moscow: NORMA, 2000. - 990 p.

[3] Bakhin V.P. Criminalistic characteristics of crimes as an element of investigation // Herald of criminalistics. - Moscow, 2000. Issue 1.

[4] Vozgrin I.A Criminalistic characteristics of crimes // Criminalistics / Ed. by T.A. Sedovoy, A.A. Eksarhopulo. St. Petersburg, 1995. - 163 p.

[5] Isayenko V.N. Criminalistic characteristics of crimes and their varieties // Criminalist, No.14 (1), 2014.

[6] Akhmedshin R.L. Criminalistic characteristics of the criminal. - Tomsk, 2005. - $251 \mathrm{p}$.

[7] Gustov, G.A, "Definition of crime" Tr. St.-Petersburg. jurid. Inst. of the Prosecutor General's Office of Russian Federation. No.2. - St. Petersburg, - 2000. - 84 p.

[8] Gavlo V.K Theoretical problems and practice of applying investigation methods of certain types of crimes. - Tomsk: TSU, 1985. - 165 with.

[9] Begaliyev E.N. Investigation of crimes committed through the forgery of material objects. Almaty: Dyke-Press, 2008. -368 p.

[10] Yakovlev A.M. Some theoretical issues of the general methodology for studying the identity of the perpetrator. Problems of eradicating crime. - Moscow, 1965. - 80 p.

[11] Poznyshev S.V. Criminal psychology, criminal types. - Moscow: Infa-M, 2007, - 302 p.

[12] Kosolapova N.V, Ivanova A.I, Legal Psychology: The Person of the Criminal. - Moscow: Yurayt, 2009. -144 p.

[13] PogoreltsevaYu.A. Personality Psychology: Training Manual / St-Pb, GTURP. -St-Pb., 2011, - 105 p.

[14] Kovalyov A.G Psychological bases of correction of the offender. The course of Soviet criminology. - M., 1968. -295 pp.

[15] Platonov K.K. The problem of abilities. - Moscow: Nauka, 1972. -312p.

[16] Alekseyev A.I. Criminology: a course of lectures. - Moscow: Schit, -M., 1999. - 340 p. 
[17] Kryukova N.I, Kostyuk M.F, Korotenkov M.P, Zulfugarzade T.E Criminology: Teachingmethodical manual. - Moscow: FGBOU VPO "RGU named after G.V Plekhanov", 2014. - 84 p.

[18] Criminology. Textbook for law High Schools. Ed. by A.I. Dolgova. M: Infra-M, 2005. - 339 p.

[19] Malkov V.D. Criminology: A Textbook for High Schools // ed. by V.D. Malkov. - 4th edition. Moscow: ZAO "Justicinform", 2011. -544 p.

[20] ByshevskyYu.V. The sex and age of the perpetrators of the theft // VestnikSeveroKavkazskogogumanitarnogoinstituta. - Stavropol, 2016. No.1.

[21] Kudryavtsev V.N, Kondrashkov N.N, Leikina N.S. and others. Identity of the criminal. - Moscow: Juridical Literature, 1969. - 356 p.

[22] Kudryavtsev V.N, Minskovsky G.M, Sakharov A.B Personality of the criminal. M.: Juridical Literature, 1975. - $272 \mathrm{p}$.

[23] Antonyan Yu. M., Kudryavtsev V.N, Eminov V.E Personality of the criminal. - St. Petersburg: Legal Center Press, 2004. -366 p.

[24] Rogov I.I, Sarsembayev M.A Criminal law (Kazakh law, international law): a textbook. - Almaty: Gylym, 1998. - 304p.

*Corresponding author.

E-mail address: zauresh.ayupova@ bk.ru / begaliev@ mail.ru / zhakemvd@ mail.ru 